\title{
Application Research of The Chinese Traditional Ecological Wisdom
}

\author{
Qian ZHAO, Shanghai Tongji Urban Planning \& Design Institute, China
}

\begin{abstract}
In the transition period of China's urbanization rate reached $60 \%$, the excessive stage from the traditional industrial civilization to ecological civilization is the inevitable choice. In the transition period, we cannot only absorb the western development experiences of eco-city, but also should combine China's traditional ecological wisdom from the agricultural civilization during thousands of years.

In this paper, the author analyses the concept and origin of traditional ecological wisdom, the related research status and development trend at home and abroad. Collect and select the technique or technology which is full of ecological value or representative, the ecological engineering which is time tested or benefited by ten thousand generations in certain region of China, establish a case base of the Chinese traditional ecological wisdom. On this basis, research the ecological concept, principles, strategies and methods of these cases. Construct a set of system principle to concise wisdom and draw the outline of urban soul. Finally, combining with China's environmental problems since the industrialization and the various problems encountered in the process of ecological city construction, to explore how to use the ecological wisdom spectrum guiding the sustainable studies, planning, design and management of the contemporary urban.

Through the study of this article, it has the theory significance by constructing the principle of traditional ecological wisdom. It has the cultural meaning by inheritancing the traditional culture essence. It also has the practical significance by discovering the power source of the eco-city construction in the future.
\end{abstract}

\section{Keywords}

Chinese traditional, Ecological wisdom, Application research, Sustainable

\section{The introduction}

Since the industrial revolution, with the rapid development of science and technology, human beings in all fields has made a series of achievements, but also encountered unprecedented social and ecological crisis, such as global warming, ozone depletion, environmental pollution and energy shortage, wetland degeneration, accelerate the extinction of species and land desertification, etc. Ecological crisis concerns the life and death of human society. As French ecological socialist Goetz said, "There is no doubt that ecological factors play a decisive and irreplaceable role in today's economic crisis. All the crises in modern society are rooted in and intensified by the ecological crisis.

In the recent three decades of rapid urbanization, China has absorbed the development experience of cities in the industrialized production period of the West. The monotonous urban layout and architectural 
space structure have made most cities lose their cultural heritage and at the same time lead to the deterioration of the urban environment.

At present, China's urbanization rate has reached $60 \%$, which is in the transition period of urban development. The transition from traditional industrial civilization to ecological civilization has become an inevitable choice for development. We should not only absorb the development experience of western eco-cities, but also combine the traditional ecological wisdom left over from thousands of years in China.

\section{Traditional ecological wisdom}

\subsection{Concept}

Traditional ecological wisdom refers to the profound and relatively universal part of traditional ecological knowledge system in a certain region that survives the long-term historical examination. It is the unique traditional ecological wisdom that people have gradually created and accumulated in harmony with nature and in line with local conditions in the long process of production and living practice, in combination with geographical environment, climatic conditions, local customs and cultural characteristics.

\subsection{The characteristics}

Regionality. Because the traditional ecological wisdom combines the local geographical environment, climatic conditions and cultural characteristics of local customs and customs, the traditional ecological wisdom of various regions has certain regionality, that is, with the change of external climatic and geographical conditions, the traditional ecological wisdom applied is different.

Limitations. China's traditional ecological wisdom is rich in content and profound in meaning, but at the same time, we should also be aware that some traditional ecological wisdom is adapted to the low productivity and living standard in the traditional agricultural society, and has certain limitations for today's modern society with a large population and rapid development. In modern civilized society, both social productivity and people's living standard have been greatly improved. Therefore, it is particularly important to actively explore and seek for the traditional ecological wisdom that can still be used in modern civilized society to solve the current ecological crisis.

The externalization of traditional culture. Chinese traditional culture is the model of eastern farming culture. The climate, the rain, the soil upon which agricultural life depended were not things which man could control; It is as if there is some destiny in the universe, and man can only endure and conform. Therefore, the core part of the culture produced in this environment emphasizes "the correspondence between man and nature" and "the unity of things and self". Similarly, China's traditional ecological wisdom also reflects this point.

\subsection{Status quo research dynamics}

At present, the domestic and foreign scholars on the research of the traditional ecological wisdom there is very little, only the domestic scholars have carried out a small amount of research, mainly concentrated in the field of philosophy, fengshui, Lin Jian with renmin university of China, the study of ecological intelligence around the Confucian, Taoist ecological philosophy theory, put forward to know nature, grasp the ecological law, the reasonable development and utilization of the natural environment, human and the nature harmonious get along, etc. Professor Xiang Weining from East China Normal University combined the innovation of theory with practice, summarized the characteristics of ecological wisdom, and discussed how to use ecological wisdom to know the practical activities of modern people. 


\section{Extraction of traditional ecological wisdom}

In this paper, two cases of Lijiang ancient town and Shanghai Chongming are selected, which are ancient towns with historical and cultural deposits and islands with superior ecological conditions respectively. The protection of traditional living environment is relatively complete and representative. Lijiang ancient town is located in the transition zone from the Hengduan Mountains to the Yunnan-Guizhou Plateau in the northwest of Yunnan Province. It has a pleasant climate and is known as an important relay station and Courier station on the Southern Silk Road and the Ancient Tea-horse Road. Chongming Island has a unique natural ecological environment, which provides a good ecological environment for Shanghai, an international metropolis. As the third largest island in China, the future development aims to protect the ecological environment, carry out appropriate development and achieve sustainable development, and develop ecological agriculture, green industry and tourism service industry.

\subsection{The wisdom of building communities and individual layouts}

Chongming Island traditional market town layout. Pay attention to local conditions, make full use of natural conditions, the layout and location of important market towns should be considered close to the developed waterways in order to drive the trade of goods. Because Chongming island is surrounded by water on all sides, it used to be possible to communicate with the outside world only by boat. Therefore, the large-scale market towns on the island are close to the water areas of the south and north branches of the Yangtze River or the river port and other places with convenient water transportation, and take advantage of water transportation to transport and distribute the goods inside and outside the island. Chongming Island used to have about seventy market towns every three or four miles. Take the more prosperous market towns as an example: Qiao Town, Miao Town, Bao Town and Bang Town are four large commercial towns in the history of Chongming Island. They are called "Qiao Miao And Bao Bang" and are located on the Banks of the south and north branches of the Yangtze River respectively. They are the main ports from Chongming to Shanghai, Jiangsu and other parts of China, with exceptionally developed water transportation.

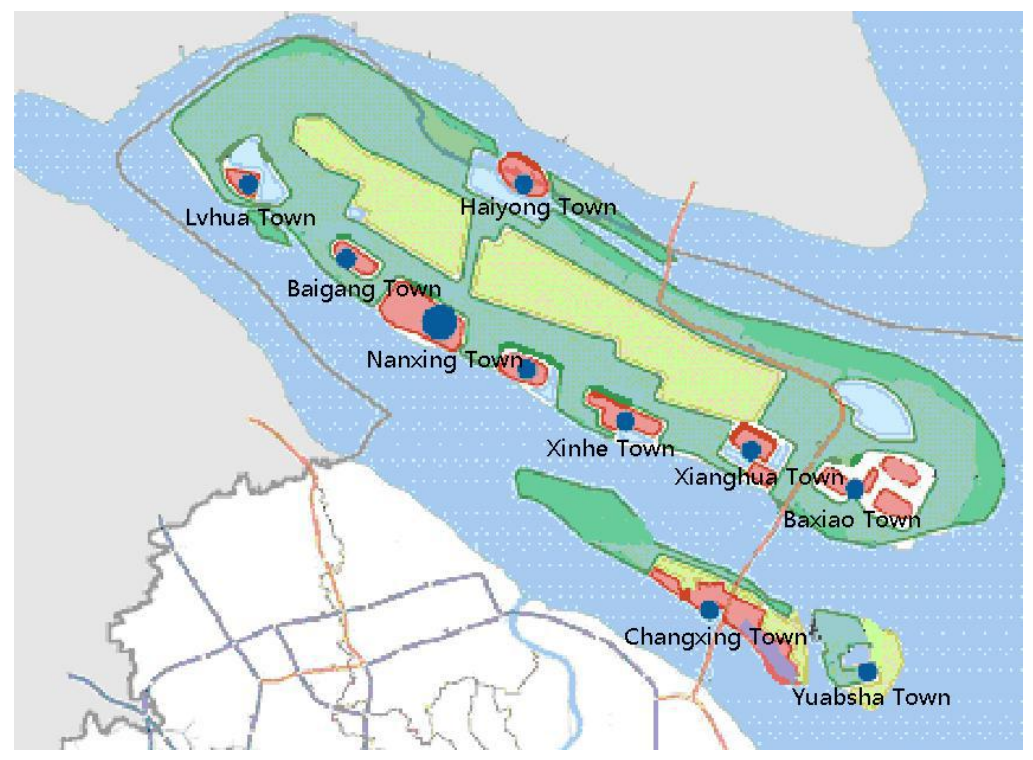

Figure 1. Layout diagram of Chongming Island market town. Source: The author since the draw.

Relationship between village community and place of production. The river on Chongming Island is vertical and horizontal, which is a typical spatial pattern of water towns. The typical layout pattern is the strip layout along the river and road. Generally, the north of the house is the village road, and the south of the house is the production place. Therefore, the life and production traffic can be solved by the 
shortest route. Curtilage east curtilage west is mingou river, can conveniently meet the production and domestic water. In general, the distance between east and west is about $60 \mathrm{~m}$, while the distance between south and north is about $300 \mathrm{~m}$.

Relationship between town community and river course. Most of the building communities in chongming Island market town are built along the river. The overall pattern not only follows the characteristics of jiangnan water town, but also differs from jiangnan. The houses on the side of the street are kept at a distance from the Banks of the river because of the high sediment content of the soil on the island, which is prone to soil erosion. This arrangement is not only convenient for loading and unloading of cargo by passing ships, but also conducive to the movement of residents and vehicles. At the same time, it conforms to the geographical conditions of Chongming Island.

The architecture of the ancient city of lijiang, was "nine, three, nine of the nine weft, by way of nine tracks the influence of traditional founding of the central plains thought, but a street along the river by water by potential room, and the water was like peas and carrots, some in front of the canal, some house besides, some building built across a river, some water diversion in hospital, all comply with the natural geography, produce the rich variety of changes in the water model. In the southeast of the ancient city, there is a place called water and houses are interlocked. In the treatment of the relationship between buildings and water, it fully embodies the idea of "conformal and stop smelting," "according to local conditions smelting," "harmony between man and nature".

\subsection{The wisdom of individual dwellings}

- Four hall curbside folk dwellings.

Four-hall curcum-type dwelling houses refer to curcum-curcum-ditches with a width ranging from 4 to $10 \mathrm{~m}$, which are dug around the curcum-ditches after the homestead is determined at the time of building, and are called four-hall curcum-ditches. Then build a house on the homestead, the homestead is similar to the siheyuan in the north, the residence is generally three compartments, four compartments, there are also three into the two Chambers, four into the three courtyard. Generally a house a surname live, also have two surname three surname live. The ecological wisdom contained therein is as follows:

The main room faces south. Traditional folk dwellings in Chongming are mostly arranged in the south, and the main room as the main house is generally arranged in the way of sitting in the north facing south, so that better sunshine can be obtained in winter for lighting and heating. In addition, the doors and Windows open in the south, so as to avoid cold wind in winter and cool in summer.

Good windproof enclosed space. Surrounded by the form of space so that the house has a good ability to avoid the wind, can effectively avoid the winter wind infringement.

A compound with the ability to regulate thermal microclimate. The courtyard form in the house can make the air in the hospital constantly exchange with the clean fresh air in the higher place, and the hospital can always maintain a relatively good air quality. The regulating capacity of thermal microclimate purifies the air quality in hospital and achieves the balance of natural ecology in a small range.

Four hall curtilage ditch. Four hall curtilage to ensure the domestic water of each family, at the same time in the water of four hall curtilage, can be stocked with white fish, silver carp, etc., can also plant lotus root. Encounter rain, residential water can be discharged into the ditch. It provides the residents with the convenience of daily life. In addition, before the liberation of Chongming Island security is not good, the island was a place where thieves gathered, so residential buildings need to consider anti-theft measures. In front of the house, a small bridge will be built, which can be put out in the morning for people to access, and withdrawn in the evening, so that the house can be kept isolated from the outside world. The four-hall house gully takes advantage of the terrain to play a protective role similar to a moat. 
Stack the house foundation against moisture. The earth excavated from the trench of four hall houses will be piled up on the house foundation to make it higher than the surrounding, thus playing a role in preventing the invasion of the sea tide.

One window, one ta ta's structure. A window: A TA ta means that a two-door width frame is installed on the side compartment roof on the side wall opposite the field center. A column is set in the middle that can be removed. A single door is set on one side. The lower half is a "TA" fan, fixed on one side of a post and half on a door frame. This structure is a strict portal system to cope with the old Chinese residential houses. Generally speaking, the door of other building inside curtilage includes kitchen house should be single "door". Ordinary folk houses in rainy days, once the kitchen door is open there will be wind and rain, wet the house. And closing it will block the light and cause the room to be dark. The structure of $A$ Ta Ta: Light can be obtained when it rains by opening the window on a ta ta. When faced with an important event at home, the ta ta can be removed from the column and removed from the following. Thus, it can freely move cloth machines, furniture, etc., within the frame of two single-door wide doors.

- Circular cave dwelling houses.

Huandong House is one of the earliest forms of dwelling houses on Chongming Island. In the past, most of them were inhabited by poor families. They were simple houses made of reeds. Using reeds to make bunches of wood, the two ends are inserted into the earth in a semicircle, and the middle dome is covered with reeds and weeds, forming a ring-shaped building. However, there are large defects in many aspects, such as sun shading and rain shelter, which disappeared in the late 1950s. The ecological wisdom contained therein is as follows:

Local materials. As an alluvial island in the estuary, Chongming's geographical conditions determine the lack of building materials on the island. In addition to a large number of reeds and aquatic plants, it is difficult to find other materials for building houses on the beach and wetland. The use of reed as building materials in Huandong houses maximizes the potential of local resources and saves the expensive material cost and transportation cost of importing bricks and tiles from outside the island.

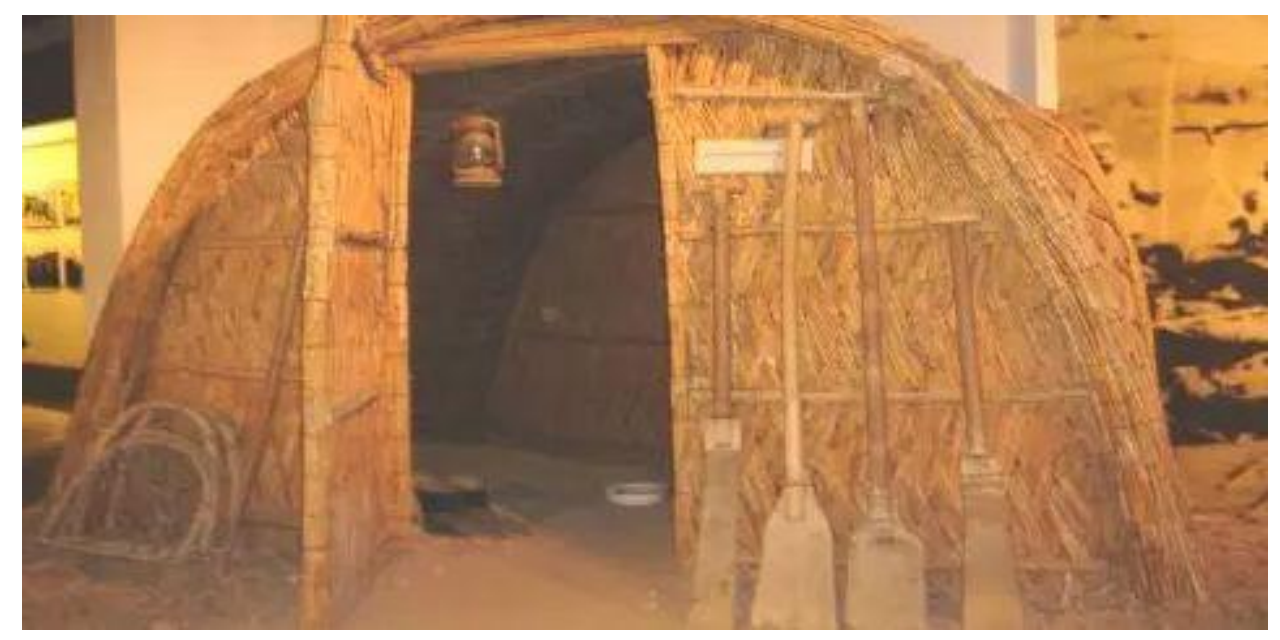

Figure 2. Circular cave dwelling houses. Source: http://city.eastday.com/gk/20180528/u1a13938569.html.

Reasonable choice of building materials. The use of reed as a building material is more in line with the actual situation of Chongming than that of brick and wood materials, because the foundation bearing capacity of the surrounding land in Chongming Xinhuan is difficult to bear the weight of the brick and wood structures. 
Circular roof. The roof of the circular cave house adopts the form of an arc rarely seen in architecture. The wind on Chongming Island is very strong, especially in summer and autumn, when typhoons occur frequently. The rounded form of the roof is a good counter to hurricanes.

\subsection{The wisdom of landscape conservation and utilization}

Chongming traditional residence attaches great importance to green configuration. Generally in the east of the house along the kind of peach willow, peach red willow green, conducive to viewing, and small tree crown, easy to transmit light; In the west side of the house to plant elm - elm adsorption gas smoke, purification of the air role; Plant bamboo and locust trees in the north and south of the house respectively to take their good cultural implication. In spring and summer, bamboo gardens and trees attract birds, while fish swim up and down in the gully, and the gully water ripples to create a rich and varied landscape.

According to the characteristics of the high terrain in the northwest and the low terrain in the southeast of the ancient city and the water system of the ancient city, The Naxi people started the tradition of "washing and smelting streets with river water" in Sifang Street, which lasted until the 1940s. Sifang Street is about $70 \mathrm{~m}$ long from east to west and $20 \mathrm{~m}$ wide from north to south. Its plane is an irregular trapezoid with The West River crossing at one end. Naxi people set up deep channels for sluice water under two Bridges that flow through Sifang Street. Every morning in the evening, the boards will be lowered to intercept the water flow, so that the water level of Xihe rises above the riverbed, and the high northwest and low southeast of the ancient city will be utilized to achieve the purpose of cleaning the ancient city.

Water is the soul of Lijiang old town. Based on the worship of water, the residents of the ancient city have a lot of water conservation and water folklore, which contains rich ecological wisdom. For example: In order to protect the river water that can be drunk directly, do not go to the river before 10:00 am to wash clothes and dirty things; Garbage and feces cannot be directly poured into the river; In water sources and near rivers, there are taboos against spitting, making a loud noise, or cutting down trees. And so on. In order to protect the water system, Naxi people have created many ways to use water, among which sanyan is the most typical one. Water for a glance, the highest terrain, can only be used for drinking; The water of two eyes is slightly lower, can wash vegetable; The third eye is the lowest, used for washing clothes and so on. Finally, the water from the well flows out of the third well and into the canal, which is used to irrigate farmland. Besides drinking, washing vegetables and washing clothes, sanyanjing is also a place for people to relax and enjoy themselves. It draws a picture of harmony between man and nature.

\section{Conclusion}

Traditional ecological wisdom not only contains reasonable ecological values, but also is the quintessence of traditional culture after long-term social practice. Through analysis and refinement, the traditional ecological wisdom in the planning and architectural layout of Chongming Ecological Island and Lijiang ancient town is presented. Systematically sorting out the ideological content of traditional ecological wisdom in various regions is conducive to a more systematic and clear understanding of the overall structure and context of traditional ecological wisdom, and filling in the gap of traditional ecological wisdom theory in the construction of ecological theory system. In the future planning and architectural layout development, these ecological wisdom can be inherited and carried forward. Learning from it and summarizing and improving its application in modern urban and rural production and life will be beneficial to its ecological and green building development. It has a strong pertinence for solving the 
current challenges in the construction of ecological smart city and will be an important source of driving force for future development.

\section{References}

Zhu Peilin. The Continuity and inheritance of the Ecological W isdom in traditional dwelling, South Architecture, 2012(6), P55-58.

Nie Liancai. To explore the layout of traditional Chinese architectural environment, Higher education research, 2003, 66(1),P30-33.

Liu Juan, Nie Xinyu, LI Hong. Thinking of traditional Residential Ecological architecture experience, Sichuan Architecture, 2011,31(4), P105-106.

Fang Ren, Green Road is the best way to develop Chongming Island, The regional economy, P50-53.

Xu Jianhe, WANG Jun, Yan Jun. Experience and enlightenment on the ecological wisdom of traditional settlements in Southern Hunan, Sichuan Building Science, 2010,36（5）,P234-236.

Liang Zhiyao, Zhao Neng. Research on the Living environment of traditional settlements, Building technology and design, 2007(12) ,P118-123.

Li Ning, Li Lin. Analysis on the composition and characteristics of traditional settlements, Journal of architecture, 2008(11),P52-55.

Liu Zheng, Li Lijuan, Zhao Xiaona, Wang Wei. Ecological Wisdom of Traditional Settlement and Residence in Hetao Plain, South Architecture, 2010(5), P56-59.

Sun Yangxu, Tang Xiaoxiang. Analysis on Ecological Wisdom of Guangfu Traditional Settlement in Lingnan Area, Architectural Culture of HUAZHONG ARCHITECTURE, 2012(10), P164-168.

Yu Zhengrong, M. (1996) Ecological wisdom theory. Beijing: China Social Sciences Press.

Ji Xueming, Wu Zhichong. To build Chongming into a state-level green ecological island -- Some ideas of cross-century development of Chongming Island. Exploration and research, P26-27.

Li Ning, Li Lin. Analysis on the composition and characteristics of traditional settlements, Journal of architecture, 2008(11), P52-55.

Liang Zhiyao, Zhao Neng. Research on the Living environment of traditional settlements, Building technology and design, 2007(12), P118-123.

Liu Guodong, Tian Yankun, YUAN Xingzhong, Sun Jinfang. Chinese Traditional Ecological Wisdom and its Practical Significance -- A Case study of Lijiang's old Town Water system, Acta ecologica sinica, 2014(07). 